\title{
Lubiprostone, a novel laxative, might improve hyperphosphatemia without water dilution
}

\author{
Shiko Gen*, Kanako Nobe and Naofumi Ikeda
}

\begin{abstract}
Background: Hemodialysis patients often develop constipation due to dietary restriction and the use of phosphate and/or potassium binders. Lubiprostone is a novel laxative that promotes defecation by activating the chloride ion channel 2 (ClC-2) in the gastrointestinal tract. While lubiprostone has been reported to be useful in bowel control of dialysis patients, no studies have examined changes in electrolyte levels following administration of lubiprostone.

Methods: We prospectively compared stool frequency and electrolyte levels before and after treatment with lubiprostone in 28 hemodialysis patients treated with the drug for at least 3 months in our hospital.

Results: Mean \pm standard deviation of stool frequency was significantly increased from $1.8 \pm 1.3$ times/week before treatment to $4.3 \pm 1.8$ times/week at Month 1, $4.9 \pm 1.9$ times/week at Month 2, and 4.5 \pm 1.5 times/week at Month 3 $(p<0.001, p<0.001$, and $p<0.001$, respectively). With regard to electrolyte levels, only serum inorganic phosphorus (IP) level was significantly decreased, from $4.7 \pm 1.5 \mathrm{mg} / \mathrm{dL}$ at baseline to $4.5 \pm 1.6 \mathrm{mg} / \mathrm{dL}$ at Month $1,4.0 \pm 1.3 \mathrm{mg} / \mathrm{dL}$ at Month 2, and $3.8 \pm 1.1 \mathrm{mg} / \mathrm{dL}$ at Month $3(p=0.123, p<0.001$, and $p<0.001$, respectively). Lubiprostone not only improved bowel control, but also decreased serum IP levels in hemodialysis patients.
\end{abstract}

Conclusions: Lubiprostone may improve prognosis of hemodialysis patients through bowel control and a decrease in serum IP.

Keywords: Hemodialysis, Lubiprostone, Serum phosphorus level

\section{Background}

Hemodialysis patients have a higher prevalence of constipation than patients with normal renal function, due to dietary restriction, fluid restriction, and use of phosphate and/or potassium binders [1]. Given the risk of hypermagnesemia due to the use of magnesium oxide preparations, which are saline laxatives [2], hemodialysis patients often use sennosides, which are stimulant laxatives. However, chronic use of these compounds can result in difficulties with bowel control due to resistance [3].

Lubiprostone is a novel laxative that promotes defecation by activating the chloride ion channel $2(\mathrm{ClC}-2)$ on the apical membrane of the small intestinal epithelium, thereby increasing water secretion into the intestinal lumen to soften feces and enhance intestinal transit.

* Correspondence: shikou-gen@sayamahp.org

Department of Nephrology, Saitama Sekishinkai Hospital, 1-33 Unoki, Sayama-shi, Saitama 3501323, Japan
While some studies have reported the usefulness of lubiprostone in bowel control of dialysis patients [4], none have examined associated changes in electrolyte levels in these patients.

Here, we investigated changes in electrolyte levels in hemodialysis patients after treatment with lubiprostone.

\section{Methods}

Among 396 patients who underwent hemodialysis in our hospital between August 2014 and August 2015, 44 (9\%) patients were administered lubiprostone to treat constipation. After excluding 16 patients who dropped out for reasons such as nausea and loss of appetite, 28 who had used the compound for at least 3 months and gave informed consent to participate were included in the study. This prospective observational study was approved by the Ethics Review Board of Saitama Sekishinkai Hospital. 
Table 1 Baseline characteristics of patients

\begin{tabular}{ll}
\hline $\begin{array}{l}\text { Number of enrolled patients } \\
\text { Age, years }\end{array}$ & 28 (14/14) \\
Duration of dialysis, years & $69.4 \pm 14.2$ \\
Underlying disease of renal failure & Diabetic nephropathy, 11 patients \\
& Chronic glomerulonephritis, 3 patients \\
& Nephrosclerosis, 5 patients \\
& Autosomal dominant polycystic kidney \\
& disease, 1 patient \\
& Primary hyperparathyroidism, 1 patient \\
& Unknown, 7 patients \\
& 17 patients \\
& Stimulant laxative, 17 patients \\
& Sugar laxative, 1 patient \\
Concomitant laxative & 18 patients \\
& Calcium carbonate, 8 patients \\
& Lanthanum carbonate, 12 patients \\
Bixalomer, 2 patients & Ferric citrate hydrate, 1 patient \\
Cinacalcet, 4 patients
\end{tabular}

Even after starting treatment with lubiprostone, patients continued to take any oral laxatives they had been using before treatment, with no changes in dosage. Lubiprostone was started at an initial dose of $24 \mu \mathrm{g}$ once daily after dinner and was then adjusted based on defecation frequency. The following parameters at months 1, 2, and 3 of treatment with lubiprostone were compared with those before treatment (baseline): mean weekly stool frequency; stool consistency (Bristol Stool Form Scale); serum levels of sodium (Na), potassium (K), corrected calcium (Ca), and inorganic phosphorus (IP); and Geriatric Nutritional Risk Index (GNRI) for nutritional assessment [5].
Serum levels were determined via laboratory tests performed at the start of each week, and corrected Ca was calculated using Payne's formula. No changes were made to any non-laxative oral drug doses or dialysis condition throughout the study.

All data are presented as mean \pm standard deviation. The Wilcoxon signed-rank test was used to compare two groups (continuous variables) at a significance level of 0.05. All statistical analyses were performed using SPSS Version 22.0 (IBM, Tokyo, Japan).

\section{Results}

Baseline characteristics of patients are shown in Table 1. A total of 28 patients (14 men and 14 women; mean age, $69.4 \pm 14.2$ years) were included in the study. Mean duration of dialysis was $7.7 \pm 9.1$ years. Underlying causes of renal failure were diabetic nephropathy in 11 patients, nephrosclerosis in 3, chronic glomerulonephritis in 5, autosomal dominant polycystic kidney disease in 1, primary hyperparathyroidism in 1, and unknown in 7 . Seventeen patients had used laxatives, and 18 patients had used phosphate binders (e.g., calcium carbonate, lanthanum carbonate) and/or cinacalcet.

After starting treatment with lubiprostone at an initial dose of $24 \mu \mathrm{g}$, the dose level was increased to $48 \mu \mathrm{g}$ in two divided doses per day after breakfast and dinner in 10 patients due to poor bowel control. Results at baseline and months 1,2 , and 3 of treatment are shown in Table 2. Stool frequency was significantly increased from $1.8 \pm 1.3$ times/week at baseline to $4.3 \pm 1.8$ times/week at month 1, $4.9 \pm 1.9$ times/week at month 2 , and $4.5 \pm 1.5$ times/week at month $3(p<0.001, p<0.001$, and $p<0.001$, respectively). The Bristol Stool Form Scale score was significantly increased from $2.3 \pm 1.0$ at baseline to $3.4 \pm 0.7$ at month $1,3.5 \pm 0.8$ at month 2 , and $3.6 \pm 0.6$ at month 3 $(p<0.001, p<0.001$, and $p<0.001$, respectively). While no significant changes were noted in serum $\mathrm{Na}, \mathrm{Cl}, \mathrm{K}$, or

Table 2 Comparison of stool and serum parameters of hemodialysis patients before and 1, 2, and 3 months after treatment with lubiprostone

\begin{tabular}{|c|c|c|c|c|c|c|c|}
\hline \multirow[t]{2}{*}{ Parameter } & \multirow{2}{*}{$\begin{array}{l}\text { Before treatment } \\
\text { Mean } \pm \text { SD }\end{array}$} & \multicolumn{2}{|l|}{ Month 1} & \multicolumn{2}{|l|}{ Month 2} & \multicolumn{2}{|l|}{ Month 3} \\
\hline & & Mean \pm SD & $p$ value & Mean \pm SD & $p$ value & Mean \pm SD & $p$ value \\
\hline Stool frequency (times/month) & $1.8 \pm 1.3$ & $4.3 \pm 1.8$ & $p<0.001$ & $4.9 \pm 1.9$ & $p<0.001$ & $4.5 \pm 1.5$ & $p<0.001$ \\
\hline Bristol Stool Form Scale & $2.3 \pm 1.0$ & $3.4 \pm 0.7$ & $p<0.001$ & $3.5 \pm 0.8$ & $p<0.001$ & $3.6 \pm 0.6$ & $p<0.001$ \\
\hline Serum Na (mEq/L) & $137.3 \pm 3.3$ & $137.5 \pm 3.0$ & $p=0.963$ & $138.2 \pm 3.5$ & $p=0.070$ & $138.2 \pm 4.0$ & $p=0.180$ \\
\hline Serum Cl (mEq/L) & $102.6 \pm 4.0$ & $103.0 \pm 3.0$ & $p=0.434$ & $103.1 \pm 3.6$ & $p=0.504$ & $103.0 \pm 3.2$ & $p=0.743$ \\
\hline Serum K (mEq/L) & $4.4 \pm 0.7$ & $4.4 \pm 0.7$ & $p=0.873$ & $4.3 \pm 0.6$ & $p=0.415$ & $4.3 \pm 0.6$ & $p=0.626$ \\
\hline Serum Ca (mg/dL) & $9.2 \pm 0.6$ & $9.1 \pm 0.6$ & $p=0.159$ & $9.2 \pm 0.6$ & $p=0.608$ & $9.2 \pm 0.6$ & $p=0.499$ \\
\hline Serum IP (mg/dL) & $4.7 \pm 1.5$ & $4.5 \pm 1.6$ & $p=0.123$ & $4.0 \pm 1.3$ & $p<0.001$ & $3.8 \pm 1.1$ & $p<0.001$ \\
\hline Geriatric nutritional risk index & $85.6 \pm 12.8$ & $85.4 \pm 11.9$ & $p=0.501$ & $86.2 \pm 11.9$ & $p=0.220$ & $86.4 \pm 11.1$ & $p=0.061$ \\
\hline
\end{tabular}

SE standard deviation, Na sodium, $\mathrm{Cl}$ chloride, $K$ potassium, $\mathrm{Ca}$ calcium, IP inorganic phosphorus 
corrected Ca levels between baseline and month 1, 2, or 3, the serum IP level was significantly decreased from $4.7 \pm$ $1.5 \mathrm{mg} / \mathrm{dL}$ at baseline to $4.5 \pm 1.6 \mathrm{mg} / \mathrm{dL}$ at month $1,4.0 \pm$ $1.3 \mathrm{mg} / \mathrm{dL}$ at month 2 , and $3.8 \pm 1.1 \mathrm{mg} / \mathrm{dL}$ at month $3(p$ $=0.123, p<0.001$, and $p<0.001$, respectively). No significant changes were noted in GNRI between baseline and month 1, 2, or 3 .

\section{Discussion}

This study showed that lubiprostone not only improved bowel control but also decreased serum IP levels in hemodialysis patients.

Hemodialysis patients have a high prevalence of constipation due to dietary restriction, fluid restriction, and use of phosphate binders [1]. It has been reported that constipation is associated with an increased risk of death from cardiovascular disease (CVD) [6], suggesting the importance of bowel control in dialysis patients, who have a high risk of death from CVD [7]. Lubiprostone is a novel laxative that promotes defecation by activating $\mathrm{ClC}-2$ on the apical membrane of the small intestinal epithelium, thereby increasing water secretion into the intestinal lumen to soften feces and enhance intestinal transit. In the present study, lubiprostone increased the mean weekly stool frequency and the Bristol Stool Form Scale score, showing its usefulness in bowel control of dialysis patients.

Lubiprostone decreased serum IP levels in hemodialysis patients. A report evaluating the safety of lubiprostone in patients with chronic constipation found no change in serum electrolytes, including $\mathrm{Na}, \mathrm{K}$, and $\mathrm{Cl}$, before and after administration, although serum IP values were not measured [8]. In a study in mice, urinary toxins including BUN, indoxyl sulfate, and hippurate were reported to decrease with lubiprostone administration [9], which the authors speculated was due to lubiprostone-induced recovery of imbalances in the gut microbiota. The decrease in serum IP values in our study might have involved similar effects. Alternatively, the decrease might have been due to improved adherence to oral phosphate binders associated with improved bowel control following administration of lubiprostone, albeit that the oral intake of phosphorus adsorption drugs before and after lubiprostone administration was not confirmed. Decreased food intake and/or nutritional status due to nausea and/or anorexia caused by lubiprostone might also have been responsible for the decrease in serum IP, but this is implausible given the lack of change from baseline in GNRI after treatment with lubiprostone.

Since it has been reported that constipation was associated with an increased risk of death from CVD [6], bowel control may decrease the risk of death from CVD in dialysis patients. In addition, hyperphosphatemia not only induces secondary hyperparathyroidism and related abnormal bone metabolism but also increases the risk of cardiovascular complications and death through vascular calcification [10]. Serum IP control is therefore recommended to improve prognosis [11]. As such, lubiprostone may improve long-term life prognosis if it is indeed effective in controlling serum IP levels.

Several limitations of the present study warrant mention. First, our study was not designed to compare treated and untreated patients, as all patients received lubiprostone. Second, the study was a small, single-center study with a short follow-up. A definitive conclusion on the utility of lubiprostone in hemodialysis patients will require larger, longer-term studies.

\section{Conclusions}

Lubiprostone not only improved bowel control but also decreased serum IP levels in hemodialysis patients. Lubiprostone may improve the prognosis of hemodialysis patients by improving bowel control and decreasing serum IP.

\section{Authors' contributions}

SG planned the study, searched the literature, and prepared the article. $\mathrm{KN}$ and $\mathrm{NI}$ assisted in the article preparation. All authors read and approved the final manuscript.

\section{Competing interests}

The authors declare that they have no competing interests.

\section{Ethics approval and consent to participate}

This prospective observational study was approved by the Ethics Review Board of Saitama Sekishinkai Hospital, and the study protocol conformed to the provisions outlined in the Declaration of Helsinki (as revised in Tokyo 2004).

\section{Financial support}

None.

Received: 15 March 2016 Accepted: 20 August 2016

Published online: 10 November 2016

\section{References}

1. Yasuda G, Shibata K, Takizawa T, Ikeda Y, Tokita Y, Umemura S, et al. Prevalence of constipation in continuous ambulatory peritoneal dialysis patients and comparison with hemodialysis patients. Am J Kidney Dis. 2002; 39:1292-9.

2. Guerrera MP, Volpe SL, Mao JJ. Therapeutic uses of magnesium. Am Fam Physician. 2009;80:157-62.

3. Locke 3rd GR, Pemberton JH, Phillips SF. AGA technical review on constipation. American Gastroenterological Association. Gastroenterology. 2000;119:1766-78.

4. Yoshida T, Furukubo T, Tanaka C, Miyake M, Sumino K, Tanaka R, et al. Clinical efficacy of lubiprostone for constipation in patients undergoing maintenance hemodialysis. J Osaka Soc Dial Ther. 2014;32:29-32.

5. Bouillanne O, Morineau G, Dupomt C, Coulombel I, Vincent JP, Nicolis I. Geriatric Nutritional Risk Index: a new index for evaluating at-risk elderly medical patients. Am J Clin Nutr. 2005:82:777-83.

6. Honkura K, Tomata Y, Sugiyama K, Kaiho Y, Watanabe T, Zhang S, et al. Defecation frequency and cardiovascular disease mortality in Japan: the Ohsaki cohort study. Atherosclerosis. 2016;246:251-6.

7. Foley RN, Parfrey PS, Sarnak MJ. Epidemiology of cardiovascular disease in chronic renal disease. J Am Soc Nephrol. 1998;9:S16-23. 
8. Lembo AJ, Johanson JF, Parkman HP, Rao SS, Miner Jr PB, Useno R. Longterm safety and effectiveness of lubiprostone, a chloride channel (ClC-2) activator, in patients with chronic idiopathic constipation. Dig Dis Sci. 2011; 56:2639-45.

9. Mishima E, Fukuda S, Shima H, Hirayama A, Akiyama Y, Takeuchi Y, et al. Alteration of the intestinal environment by lubiprostone is associated with amelioration of adenine-induced CKD. J Am Soc Nephrol. 2015;26:1787-94.

10. Tentori F, Blayney MJ, Albert JM, Gillespie BW, Kerr PG, Bommer J, et al. Mortality risk for dialysis patients with different levels of serum calcium, phosphorus, and PTH: the Dialysis Outcome and Practice Patterns Study (DOPPS). Am J Kidney Dis. 2008;52:519-30.

11. Kidney Disease: Improving Global Outcomes (KDIGO) CKD-MBD Work Group. KDIGO clinical practice guideline for the diagnosis, evaluation, prevention, and treatment of chronic kidney disease-mineral and bone disorder (CKD-MBD). Kidney Int. 2009;76:S1-130.

Submit your next manuscript to BioMed Central and we will help you at every step:

- We accept pre-submission inquiries

- Our selector tool helps you to find the most relevant journal

- We provide round the clock customer support

- Convenient online submission

- Thorough peer review

- Inclusion in PubMed and all major indexing services

- Maximum visibility for your research

Submit your manuscript at www.biomedcentral.com/submit
Biomed Central 